\title{
The Importance of Cognitive and Mental Factors on Prediction of Job Performance in Chinese High-Speed Railway Dispatchers
}

\author{
Zizheng Guo, ${ }^{1,2,3}$ Jiaming Zou, ${ }^{1,2}$ Chuanning He, ${ }^{4}$ Xi Tan, ${ }^{1,2}$ Chongshuang Chen, \\ and Guo Feng ${ }^{6}$ \\ ${ }^{1}$ School of Transportation and Logistics, Southwest Jiaotong University, Chengdu 611756, China \\ ${ }^{2}$ National United Engineering Laboratory of Integrated and Intelligent Transportation, Southwest Jiaotong University, \\ Chengdu 610031, China \\ ${ }^{3}$ National Engineering Laboratory for Comprehensive Transportation Big Date Application Technology, \\ National Development and Reform Commission, Beijing 100000, China \\ ${ }^{4}$ Dispatch Office of China Railway Chengdu Group Co. Ltd., Chengdu 610082, China \\ ${ }^{5}$ School of Mathematics, Southwest Jiaotong University, Chengdu 611756, China \\ ${ }^{6}$ Psychological Research and Counseling Center, Southwest Jiaotong University, Chengdu 611756, China
}

Correspondence should be addressed to Guo Feng; fengguo@swjtu.edu.cn

Received 8 January 2020; Revised 20 May 2020; Accepted 29 July 2020; Published 14 August 2020

Academic Editor: Kun Xie

Copyright (C) 2020 Zizheng Guo et al. This is an open access article distributed under the Creative Commons Attribution License, which permits unrestricted use, distribution, and reproduction in any medium, provided the original work is properly cited.

\begin{abstract}
High-speed railway (HSR) transportation poses a serious challenge to dispatchers, whose job performance plays a critical role for the safety and efficiency of the transportation system. This study examined the relationship between cognitive and mental factors and job performance among Chinese high-speed railway dispatchers and established a predictive model for the job performance of dispatchers. Cognitive abilities involved in train dispatching including working memory and multiobject tracking and potential related mental factors including depression, anxiety, perceived stress, and social support were examined. Job performances were measured by both subjective and objective indicators, i.e., the overall evaluation by supervisors and the delay time by dispatching simulator. Stepwise regression results showed that both cognitive abilities and 2 mental factors (depression and perceived stress) have strong relations with job performance, and tremendous distinction between groups of good and poor performance of HSR dispatchers is revealed. The predictive model accounted for $91 \%$ of the overall variance in objective performance indicator and has $96 \%$ distinguished accuracy of good and poor groups. These findings imply that cognitive and mental factors should be of great concern to the current practice of Chinese HSR dispatcher selection and management.
\end{abstract}

\section{Introduction}

With the share of China accounting for about $2 / 3$ of the world high-speed railway (HSR) mileage [1], the daily transportation of China's high-speed trains is about 1.33 million, which occupies 25.7 percent of the overall passenger traffic [2]. The HSR dispatchers take full efficiency and safety responsibility in conducting the high-speed trains' running in the network. Railway Accident (2011) reports that in the Yong-wen railway, a severe accident of two trains' collision resulted in 40 deaths and 172 injuries partly due to the HSR dispatcher's overlook of the malfunctioned signalling equipment and his failure to deliver the correct movement authority to the trains [3]. Although aided by many automated equipment, the safe and efficient dispatching tasks still heavily rely on the HSR dispatchers' multiple capabilities and mental states in emergency situations $[4,5]$.

Previous research studies on job performance of other occupations have listed possible impact factors: (1) at the level of organization, including the work environment, assessment system, incentive mechanism, and corresponding training $[6,7] ;(2)$ at the individual level, including but not limited to job-related knowledge, professional skills, capabilities, stress, and emotional state $[8,9]$. These impact 
factors have different predictive effects according to the variety of occupations. As an emerging occupation, HSR dispatching has its own particularity. Hence, we discussed the predictive factors of HSR dispatchers' job performance from the perspective of work analysis.

As the central nervous system of train operation, HSR dispatcher is not only responsible for daily adjustment of train operation, dispatching order issuing, tracking, and controlling the train route but also needs to dispose all kinds of emergencies quickly at any time. Highly complex and important work content, which reduces the prediction of job performance of ordinary tests concentrated on job-related knowledge, professional skills, and capabilities [10, 11], makes the establishment of strict selection and training system as a must [12-14]. The predictive validity of the cognitive ability depends on the complexity of the job with the strongest validity coefficients observed for highly complex jobs $[15,16]$. Literature $[17,18]$ and task analysis of Chinese HSR dispatchers both reveal that train dispatching is a highly cognitively demanding task [19]. We first summarized HSR dispatchers' job responsibilities and the related cognitive abilities in Table 1.

Among cognitive abilities, working memory and multiobject tracking caught our considerable attention given their highly frequent requirements in HSR dispatcher's job. Working memory can be defined as a temporary retention of representations that were just recently experienced (but no longer exist in the environment) or recalled from long-term memory [20]. Working memory ability is viewed as one of the most important psychological constructs extensively investigated in the cognitive psychology [21-23] and is more highly correlated with the job performance than others constructs like the intelligence [24]. Working memory has been proved to be a better predictor than others, especially under the similar job cognitive requirements situation of air traffic control system [25]. N-back task is often employed to measure the working memory ability $[26,27]$.

The multiobject tracking ability is also repeatedly reported to be important in facilitating job efficiency by improving the adequate situational awareness on performance from monitoring tasks and multitasking activities [28, 29]. The multiobject tracking ability is viewed as an important factor for air traffic controllers' selection and training [30]. The multiobject tracking (MOT) task is used generally to examine the multiobject tracking ability of various professional capabilities $[31,32]$. As seen from the job responsibilities of the HSR dispatchers, the multiobject tracking abilities are also a suitable factor to predict the job performance. Because many tasks such as routing, monitoring, and managing emergency require searching and tracking multisource information on the control panel, visual tracking of dynamic objects is an important component of the HSR dispatching. In conclusion, we assume that the multiobject tracking ability should be included into the cognitive abilities set.

In addition to cognitive abilities, a series of studies showed that mental health also impacts job performance. In the field of traffic safety, drivers with mental problems have much worse driving performance in both simulator and road tests, for depression and anxiety could slow down reaction speed and increase accident rates [33-35]. Similar results have also been found in nurses and operating workers [36, 37]. Though it has been widely confirmed $[33,36,38,39]$, little is known among HSR dispatchers. The particularities of HSR dispatching make mental factors to be the validity predictors of job performance. For example, HSR dispatchers had to work 12 hours in each shift and their attention and audio-visual perception must to be always highly alert while working. Moreover, the working environment is monotonous and the workplace is completely enclosed. These above unique work characters could easily lead to emotional problems such as depression and anxiety. Depression is the most prevalent emotional problem, and there is no debate about its impact on job performance [40]. Similar to depression, anxiety also plays its key role. While the absence of positive affect is specific to depression, the physiological hyperarousal is specific to anxiety [41]. Anxiety could impair employees' memory ability, cause insomnia, and make them more aggressive when communicating with others [36]. Research investigated that metro dispatchers had worse mental health than other occupation groups in terms of depression and anxiety [42].

Besides, highly cognitive demanding and safety responsibility work also lead to a state of stress. Survey report from Federal Railroad Administration (FRA) has suggested that most dispatchers perceived stress in their daily work [43]. Perceived stress, as an important composition of mental health, is always associated with negative cognitions and negative mood on the one hand $[44,45]$. On the other hand, moderate stress is necessary for HSR dispatchers to keep physiological arousal that helps constant vigilance. Hence, perceived stress need to be test as a predictor of HSR dispatchers' performance. Besides, studies have shown that social support can regulate negative emotions [46, 47] and this makes the ability to perceive social support also be a mental health factor. Therefore, factors such as depression, anxiety, perceived stress, and perceived social support were all under consideration as different dimensions of mental health in this study to support the predictive model of HSR dispatcher's job performance.

Meanwhile, cognitive factors may interact with mental factors. Previous studies have shown that mental health affects cognitive ability [48, 49]. Typically, anxiety has a negative relationship with working memory performance [50]; depression could alter reaction time of multiple cognitive abilities including working memory and attention [51]. Vice versa, cognitive ability could also affect mental factors [52, 53]. Related research found that high cognitive performance has been associated with better mental health, e.g., lower risk of psychiatric disorders [54-56]; low working memory capacity leads to an increased susceptibility to anxiety [57].

Therefore, cognitive factors including working memory and multiobject tracking and mental factors such as depression, anxiety, perceived stress, and perceived social support should be taken into account in the job performance model that needs holistic monitoring and comprehensive 
TABLE 1: The HSR dispatcher's job responsibilities and the necessary cognitive abilities.

\begin{tabular}{|c|c|c|}
\hline $\begin{array}{l}\text { Job responsibilities of } \\
\text { HSR dispatchers }\end{array}$ & Job contents/professional skills & Job-related cognitive abilities \\
\hline Schedule preparation & $\begin{array}{l}\text { Scheduling the routing and movement of trains with the } \\
\text { consideration of construction and maintenance plans }\end{array}$ & Reasoning, planning, and working memory \\
\hline Operation monitoring & $\begin{array}{c}\text { Monitoring train operation, line conditions, and weather } \\
\text { conditions }\end{array}$ & $\begin{array}{l}\text { Working memory, multiobject tracking, and } \\
\text { attention }\end{array}$ \\
\hline Information collection & $\begin{array}{c}\text { Communicating with other railway personnel regarding } \\
\text { train and track information }\end{array}$ & $\begin{array}{l}\text { Working memory, multiobject tracking, } \\
\text { sustained attention, and communication skills }\end{array}$ \\
\hline Emergency disposal & $\begin{array}{l}\text { Managing emergent events to protect the safety of the pubic, } \\
\text { railway employees, and railway property }\end{array}$ & $\begin{array}{l}\text { Working memory, multiobject tracking, and } \\
\text { situation awareness }\end{array}$ \\
\hline Data management & $\begin{array}{l}\text { Maintaining records of train movements, track } \\
\text { assignments, maintenance activities, and other events }\end{array}$ & Working memory and multiobject tracking \\
\hline
\end{tabular}

disposition, but to what extend these factors can explain the impact on performance remains unclear. To the authors' best knowledge, this research is one of the first studies to explore the quantifiable relationships between the cognitive and mental factors and the job performance in the context of HSR dispatching, especially on the prediction of the jobrelated specific cognitive abilities. It would lead to one of the theoretical and practical bases for the HSR dispatchers' candidate selection and personnel managing.

The aim of this article is to get insights into the role of the cognitive abilities and related mental factors in the HSR dispatching environment and to offer a theoretical prediction model on the job performance of the HSR dispatchers. The remaining part of this article is structured as follows. The methodology section explains the sampling techniques, the methods for measurements, and research procedures. The subsequent section is dedicated to the presentation and analysis of the results. The final section draws conclusions along with a discussion.

\section{Materials and Methods}

The HSR dispatchers were recruited from a branch of China Railway. Cognitive abilities including the multiobject tracking (MOT) and the working memory (WM) of these HSR dispatchers were measured. And mental factors including depression, anxiety, perceived stress, and perceived social support were measured through questionnaire. The conduction of the tests was in a random order across the subjects to control the carry-out effects. Their job performances were measured by both subjective indicator and objective indicator, i.e., the overall evaluation and the delay time.

2.1. Cognitive Ability Tests. Two E-prime 2.0 programmed tests were selected to measure working memory and visual multiobject tracking abilities.

2.1.1. Working Memory: 2-Back Task. One of the most frequently used methods to measure working memory ability is the n-back task [26, 27]. The 2-back task was conducted in our study. Specifically, a series of white letters (font at 48) were presented on the black background; each of them was shown for $0.5 \mathrm{~s}$ and participants were asked to determine whether it is the same as the letter that was presented two items back in the series. If the answer is same, participants were required to press "Enter" key as soon as possible; otherwise, no button should be pressed (Figure 1). The reaction time (RT, ms) and the correct accuracy (ACC) were recorded as the performance of working memory. Each participant did 6 practice trials and completed 176 trials in the formal test.

2.1.2. Multiobject Tracking (MOT) Task. Multiobject tracking (MOT) paradigms [58] are widely used to study the capability of tracking multiple moving objects simultaneously [59]. In each trial (see Figure 2), 16 squares $(1 * 1 \mathrm{~cm})$ including targets (colored red) and nontargets (colored green) appear at random locations of a $15 * 15 \mathrm{~cm}$ box. The number of targets was randomly determined ranging from one to seven. In the $5 \mathrm{~s}$ phase of attentive tracking, all targets turned green just identical to the nontargets first, and all objects started moving. Then, all objects stopped moving, and participants were asked to judge whether one randomly selected object (marked in white color) was a target or not by pressing buttons. Similar to the above test, performance was measured by the reaction time (RT) and the correct accuracy (ACC). Each participant completed 49 formal trials after they have really understood the whole task through practice trials (4-8 trials).

\subsection{Psychological Questionnaire}

2.2.1. The Zung Self-Rating Depression/Anxiety Scale (SDS and SAS). The SDS and SAS [60] are two widely used scales to quantify depression and anxiety symptoms. Each of them included 20 worded items that rated from 1-4 to assess the level of depression or anxiety, and higher scores correspond to more frequent symptoms. Both SDS and SAS have good reliability and validity $[61,62]$, and Cronbach's alpha in the current study is 0.757 and 0.82 , respectively.

2.2.2. The Perceived Stress Scale (PSS). The PSS [63] is one of the most commonly used instruments to measure stress perception. 14 items in PSS were designed to measure the extent to which one's life is perceived as "unpredictable, 


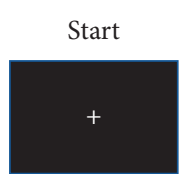

$2 \mathrm{~s}$

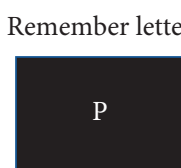

$0.5 \mathrm{~s}$

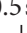

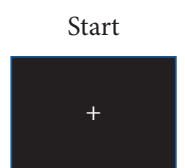

$2 \mathrm{~s}$

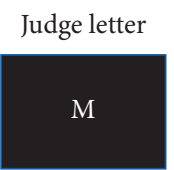

$0.5 \mathrm{~s}$

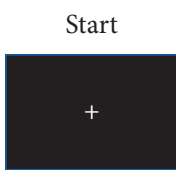

$2 \mathrm{~s}$

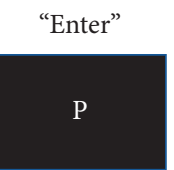

$0.5 \mathrm{~s}$

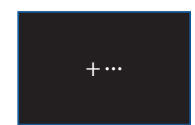

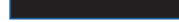

1 Trial $=2.5 \mathrm{~s}$

FIGURE 1: Illustration of the 2-back task.

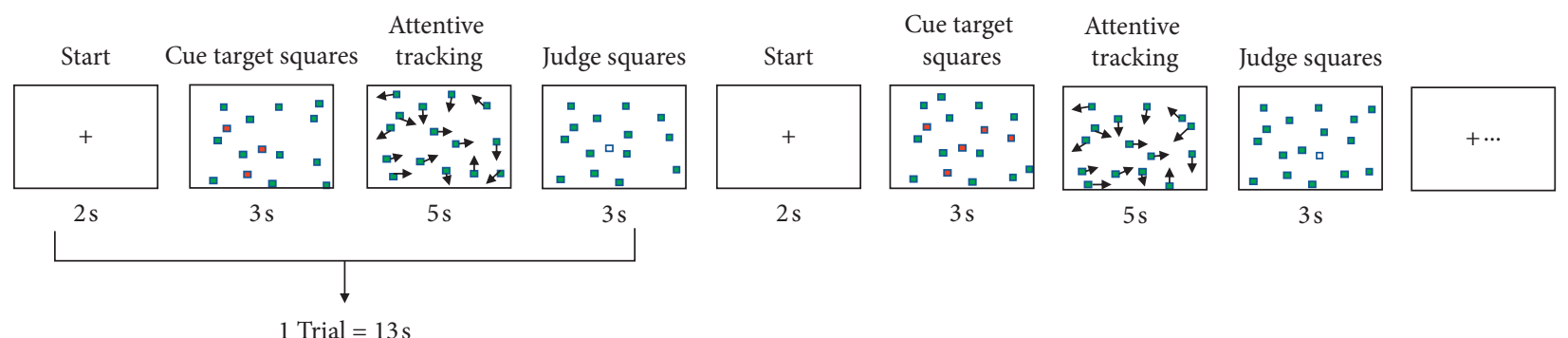

FIGURE 2: Illustration of multiobject tracking (MOT) task.

uncontrollable, and overloading." Each item was rated on a 5 -point Likert scale. Cronbach's alpha is 0.84 in this study.

2.2.3. The Perceived Social Support Scale (PSSS). The PSSS [64] is the Chinese version of Zimet's Multidimensional Scale of Perceived Social Support (MSPSS) [65] to measure actually perceived social support. It has 12 items rated on a 7-point Likert scale and is divided into three dimensions: family support, friend support, and other support. Cronbach's alpha is 0.88 in the current study.

2.3. Evaluation ofJob Performance. The HSR dispatcher's job performance was measured by both subjective indicator (overall evaluation) and objective indicator (delay time). The overall evaluation was made by their supervisors and the delay times were calculated by the HSR dispatching simulator.

2.3.1. Subjective Indicator: Overall Evaluation. The participants' overall evaluation was given by five supervisors, including two dispatching directors (from two different shifts), a technical training director, a safety director, and an administration director from the HSR dispatching station. The overall evaluation was rated on a 9-point Likert scale (1, completely poor; 2 , very poor; 3 , poor; 4 , rather poor; 5 , neutral; 6 , rather good; 7 , good; 8 , very good; 9 , completely good) through the question "Please give an overall evaluation of the dispatcher's job performance." Before the question, there was a guide paragraph that specified the scoring criteria which should be rated from HSR dispatchers' five job responsibilities including schedule preparation, operation monitoring, information collection, emergency disposal, and data management. Similar one-item measure of overall job performance has been used in previous studies $[66,67]$.

To avoid the inaccurate evaluation from the supervisors who were not familiar with the dispatchers, a 9-point Likert scale question "How well do you know the dispatcher's job performance of all five job responsibilities?" was also asked. Data from the supervisors with familiarity scores lower than 3 were excluded, which accounted for $3 \%$ of all the supervisor-dispatcher pairs. Afterwards, overall evaluation ratings from the remaining supervisors were averaged for each dispatcher.

The Pearson correlation analysis was used to examine the relations between the familiarity and the job performance $(r=0, p=1)$, which showed that the supervisors' ratings on the job performance were not likely to be affected by their familiarity with the dispatchers. Also, the $\mathrm{r}_{\mathrm{WG}}$ values of the job performance ranged from 0.93 to 1 (mean $=0.98$; median $=0.98$ ), reaching the cutoff value of 0.7 generally recommended for good inter-rater agreement [68].

2.3.2. Objective Indicator: Delay Time. Delay time is an objective indicator to reflect HSR dispatchers' job performance. In most circumstances, trains could run normal according to the operation diagram. But they would be stopped or be slowed down when encountering emergency scenarios such as equipment failure, natural conditions, or human causes, which would cause delay for minutes or even hours. Dispatchers need to ensure trains are running on time to the greatest extent when they enter the jurisdiction. Ensuring the running time of trains is an important part of dispatcher's daily shift and job performance.

To test this objective indicator while controlling all uncertain variables, we use a fully simulated dispatching simulator for data collection. The dispatching simulator was developed by the authors' team (see Figure 3), which was 
entirely designed according to real CTC dispatching system. It was installed with eight Dell computers (Precision 490, Dual Core Intel Xeon Processor $51302 \mathrm{GHz}$ ) with a $256 \mathrm{MB}$ $\mathrm{PCI} \times 16$ Nvidia graphic card, Sound Blaster ${ }^{\circledR} \mathrm{X}-\mathrm{Fi}^{\mathrm{TM}}$ system, and Dell A225 Stereo System. A 27-inch LCD screen with $1920 \times 1200$ pixel resolution was adopted to display experimental scenarios. The dispatching simulator also has a Huawei tablet that can communicate with other related HSR positions such as drivers. The tablet could respond automatically when the participant spoke. Through this simulator, the dispatcher can conduct emergency dispatching just the same as their real work. Meanwhile, the simulator will record the total delay time of trains in the dispatcher's jurisdiction caused by the dispatcher's operation response and emergency scenario.

2.4. Participants and Procedure. 70 random selected HSR dispatchers from a branch of China Railway participated in this study. All of them were males, which is consistent with the fact that almost all HSR dispatchers in China are males. They were required to avoid alcohol and caffeine on the day of experiment as well as to refrain from eating or exercising two hours before the study. Firstly, participants gave informed consent that participation was voluntary, and it would neither affect their performance evaluation nor have any other consequence in the company. Next, a questionnaire collecting demographic information was conducted, including variables that could be correlated to dispatching skills or cognitive abilities, such as age (mean $=34.76$ and $\mathrm{SD}=3.25$ years), HSR dispatching experience ranging from 1 to 9 years ( mean $=4.51$ and $\mathrm{SD}=2.22$ years), and education ( $82 \%$ had a bachelor's or higher degree), and variables that could be possibility correlated to mental factors, such as marriage ( $89 \%$ were married).

Then, all the participants completed 4 mental health tests (integrated into a long questionnaire test) and 2 cognitive tests. The order in which participants took the mental health questionnaire and cognitive tests and the order of WM task and MOT task were all random and counterbalanced. A short break of about three minutes was provided between any two tests (see Figure 4).

Next, the simulator experiment was conducted. In this part, the participants firstly spent several minutes to be familiar with the simulator until they had mastered the basic operation. Secondly, participants were informed of the emergency scenario that needs disposal. The emergency scenario designed by highly experienced HSR dispatcher was the indicator of one of the rail switches turning into a wrong status. According the operation and safety regulations, eight process were included in this situation: (1) an alarm window was popped up on the control panel and the alarm sound was broadcasted; (2) the dispatcher identified the failure and commended the HSR driver to stop the train; (3) the dispatcher confirmed the failure and started the emergency procedure on the control panel; (4) the dispatcher informed the concerned personnel to make preparation; (5) the dispatcher adjusted the train operation plan for safety protection; (6) the station attendant sent a request for track-

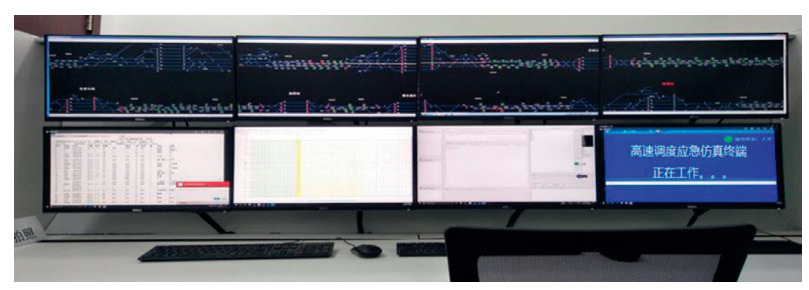

FIgURE 3: The dispatching simulator.

checking to the dispatcher who would issue the related dispatching order; (7) the dispatcher asked the on-site personnel about the situation; (8) the train operation was recovered after the failure was solved. Participants were asked to operate the simulator in actual situation to deal with the failure situation. They did the trial twice including a practice and a formal test. The delay time of all the trains in jurisdiction was obtained from the formal test. Specific operation steps are illustrated in Figure 5.

Participants operated the simulator about 2 hours that depended on their dispatching ability. Each dispatcher participant was given a gift for their participation. At last, 70 questionnaires and simulator data were validated, giving a validity rate of $100 \%$.

\section{Results}

On basis of the qualitative analysis, this section would explore the analytical relationship between the job performance and the possible variables from a quantitative perspective. As shown in Figure 6, firstly, we divided the dispatchers into the good performance group (Good) and the poor performance group (Poor) and established the threshold for them. Then, in order to establish a predictive model of the dispatcher's job performance, the stepwise regression method was adopted into model of the relation between the HSR dispatchers' job performance and the possible variables. Finally, according to the threshold and the predicted delay time, the dispatchers were identified as Good and Poor. The validity and accuracy of the model would be tested by the comparison between the predicted group and the original group. Specific data analysis procedures are shown in Figure 6.

3.1. Descriptive Statistics of All Variables. In the previous section, the job performance of HSR dispatchers was measured by the subjective and the objective indicators, i.e., the overall evaluation and the delay time. Four demographic variables (age, dispatching experience, education, and marriage), four cognitive variables (ACC of MOT, RT of MOT, ACC of WM, and RT of WM), and four mental variables (anxiety, depression, perceived stress, and social support) were the possible variables to predict the job performance. The mean and standard deviations of these variables are shown in Table 2. Among these demographic variables, "education" and "marriage" were not included in the following statistics for three reasons: (1) these two are dichotomous variables; (2) most of the answers are in one category ( $82 \%$ had a bachelor's or higher degree and $89 \%$ 


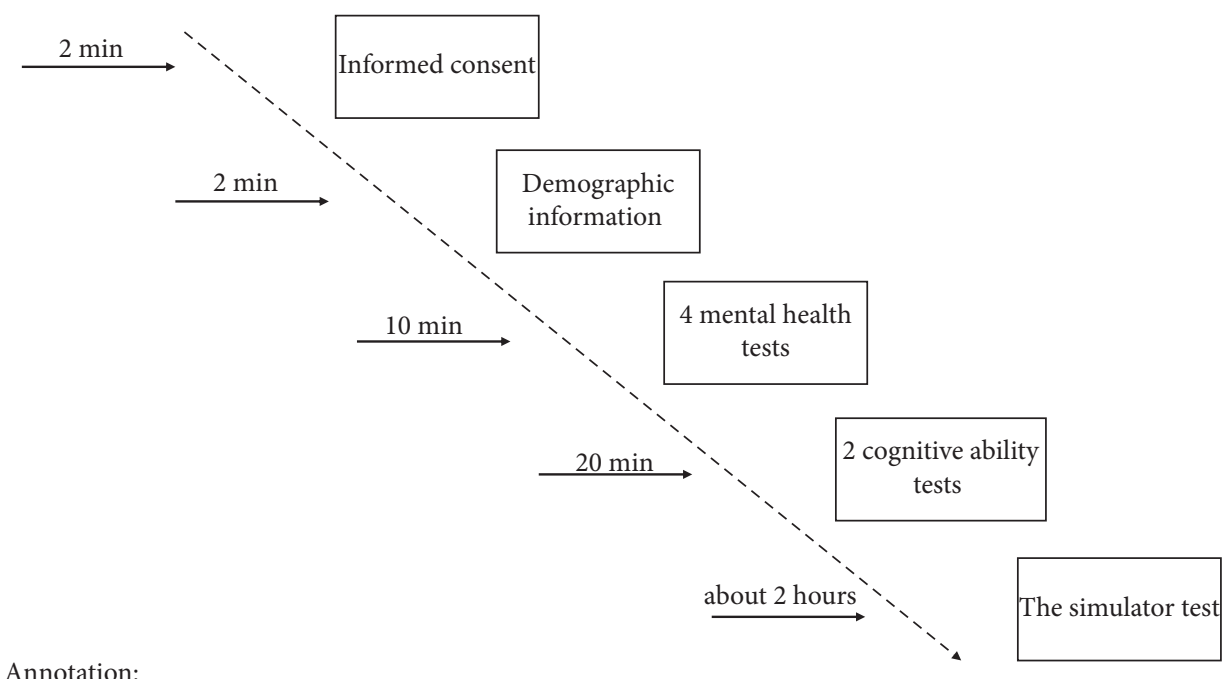

1. The order of which tests were done first was random and counterbalanced

2. Half did WM task first and the other half did MOT task first

FIgURE 4: The experimental procedures.

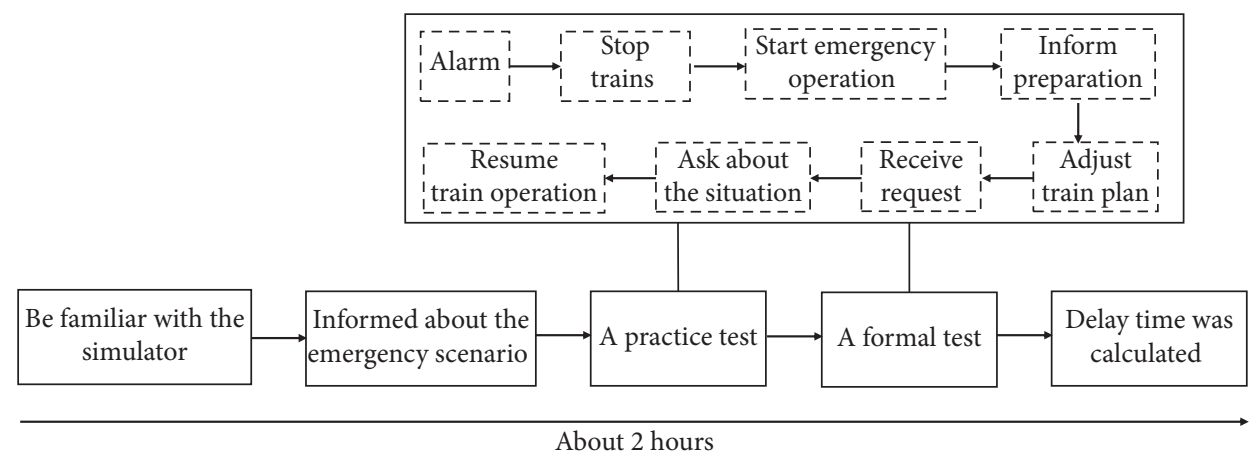

FIgURE 5: The procedures of the simulator test.

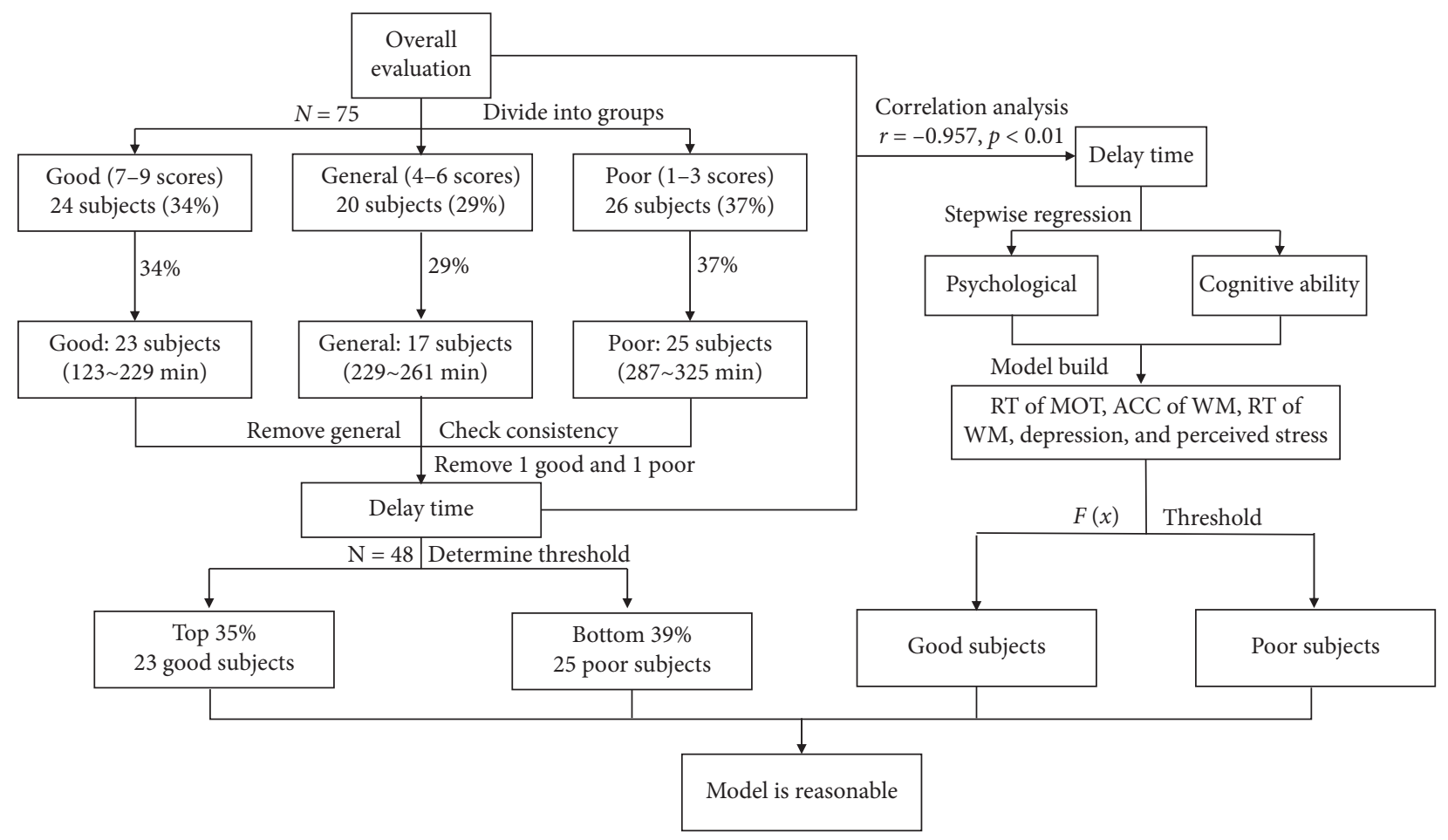

FIgURE 6: Data analysis procedures. 
TABle 2: Descriptive statistics of all variables $(n=70)$.

\begin{tabular}{|c|c|c|c|c|c|}
\hline Scale & Mean & SD & Cronbach's alphas & Category $1(\%)$ & Category $2(\%)$ \\
\hline Age (years) & 34.76 & 3.25 & - & & \\
\hline Dispatching experience & 4.51 & 2.22 & - & & \\
\hline Education & - & - & - & 82 & 18 \\
\hline Marriage & - & - & - & 89 & 11 \\
\hline ACC of MOT & 0.61 & 0.15 & - & & \\
\hline $\mathrm{RT}$ of MOT (ms) & 1288.04 & 280.18 & - & & \\
\hline ACC of WM & 0.67 & 0.22 & - & & \\
\hline RT of WM (ms) & 743.39 & 200.29 & - & & \\
\hline Depression & 42.75 & 11.57 & 0.757 & & \\
\hline Anxiety & 42.84 & 11.95 & 0.82 & & \\
\hline Perceived stress & 18.7 & 7.51 & 0.84 & & \\
\hline Social support & 55.56 & 16.91 & 0.88 & & \\
\hline Overall evaluation & 5.33 & 2.31 & - & & \\
\hline Delay time (min) & 243.31 & 55.87 & - & & \\
\hline
\end{tabular}

were married); (3) independent $t$-test showed that they did not affect other variables $(p s>0.05)$.

3.2. Group Division and Threshold Determination. The overall evaluation was a comprehensive evaluation based on the dispatcher's aggregate performance which was susceptible to the personal preferences of the supervisors. Therefore, the overall evaluation had certain subjectivity and arbitrariness. Additionally, the delay times indicated the dispatching ability of the participants to deal with emergency event by operating the simulator, which had certain volatility. As a result, the subjective indicator and the objective indicator were combined into the classification of the dispatchers and the threshold was jointly determined.

Firstly, the overall evaluation was used to stratify the groups. In order to make a large dispersion between groups, the dispatchers were stratified into three groups: Good (7-9 scores), General (general performance) (4-6 scores), and Poor (1-3 scores). In particular, 24 (34\%) were Good, 20 (29\%) were General, and 26 (37\%) were Poor, respectively. The General group was a transition part between the Good and the Poor ones, with the possibility to interfere or to misjudge the results. In this case, the General group was removed from the groups.

The participants were stratified by the overall evaluation into two groups and they were sorted according to the delay time from small to large. Since the subjective indicator had certain subjectivity and arbitrariness, the delay time was used to examine the group consistent with overall evaluation. The top $34 \%$ of the delay time was stratified into the Good group, and the bottom 37\% was stratified into the Poor group. The participant would be removed when the group of delay time was inconsistent with the group of overall evaluation. In this case, a total of 2 (4\%) participants were removed, indicating that the subjective indicator and the objective indicator are of practical unanimity $(r=-0.957$, $p<0.01)$. In the end, the final sample of 48 dispatchers was obtained from 70 valid data, including 23 Good and 25 Poor ones.

Finally, to make clear the predicted values obtained by the stepwise model in Section 3.4 belong to the Good or Poor group, it was necessary to determine the threshold. Given the groups had been consistently confirmed by overall evaluation and delay time, the maximum delay time $(229 \mathrm{~min})$ in the Good was adopted as the threshold. When the predicted value was $229 \mathrm{~min}$ or less, the participant was part of the Good group. In other words, when the predicted value was greater than $229 \mathrm{~min}$, the participant was classified into the Poor group.

After grouping, the results of the difference in the demographic variables and the cognitive variables between Good and Poor are presented in Table 3. Two demographic variables, four cognitive variables, and four mental variables were significant differences between Good and Poor $(p s<0.05)$.

3.3. Correlation of Variables. Two-tailed Pearson correlation analysis was performed to examine the relationship among independent variables (including demographic variables, cognitive variables, and mental variables) and dependent variables (both subjective and objective indicators). As shown in Table 4, the correlation between all independent variables and dependent variables was significant with absolute correlation coefficients ranging from 0.35 to 0.91 $(p s<0.05)$, which provided basis for establishing regression model for next step. And significant correlations were found between most independent variables. This indicated a multicollinearity relationship between these variables, and this provided basis for stepwise regression. There was a strong correlation between overall evaluation and delay time ( $r=-0.95, p<0.01)$; therefore, we only used the delay time (objective indicator) as dependent variable in the predictive model.

3.4. Stepwise Regression Model. In this study, the stepwise regression model was established to identify the variables contributing to the delay time. Eleven variables were entered in the process of stepwise and a total of five regression models were established. The model with the best fitting effect which is presented in Table 5 contained five variables: ACC of WM $(\beta=-0.33, p<0.01)$, RT of WM $(\beta=0.27$, 
TABLE 3: Comparison of demographic variables and cognitive variables between two groups $(n=48)$.

\begin{tabular}{lcccc}
\hline Measures & $\begin{array}{c}\text { Group (mean and standard deviation) } \\
\text { Good }(N=23)\end{array}$ & $\begin{array}{c}\text { Statistics } \\
\text { Poor }(N=25)\end{array}$ & $P$ value \\
\hline Age & $36.35 \pm 4.31$ & $33.84 \pm 2.01$ & $2.55^{\mathrm{a}}$ & $0.02^{*}$ \\
Dispatching experience & $5.61 \pm 1.99$ & $2.52 \pm 0.92$ & $6.80^{\mathrm{a}}$ & $0.00^{* *}$ \\
ACC of MOT & $0.730 \pm 0.09$ & $0.53 \pm 0.14$ & $5.65^{\mathrm{a}}$ & $0.00^{* *}$ \\
RT of MOT (ms) & $1070.91 \pm 183.02$ & $1522.46 \pm 237.96$ & $-7.32^{\mathrm{a}}$ & $0.00^{* *}$ \\
ACC of WM & $0.92 \pm 0.12$ & $0.47 \pm 0.06$ & $15.66^{\mathrm{a}}$ & $0.00^{* *}$ \\
RT of WM (ms) & $595.09 \pm 152.0$ & $948.14 \pm 32.86$ & $-10.91^{\mathrm{a}}$ & $0.00^{* *}$ \\
Depression & $31.70 \pm 6.28$ & $52.20 \pm 7.42$ & $-10.29^{\mathrm{a}}$ & $0.00^{* *}$ \\
Anxiety & $34.02 \pm 8.30$ & $51.65 \pm 10.96$ & $-6.24^{\mathrm{a}}$ & $0.00^{* *}$ \\
Perceived stress & $13.65 \pm 5.80$ & $22.04 \pm 7.20$ & $-4.42^{\mathrm{a}}$ & $0.00^{* *}$ \\
Social support & $64.22 \pm 11.62$ & $52.40 \pm 18.20$ & $2.70^{\mathrm{a}}$ & $0.01^{*}$ \\
\hline
\end{tabular}

${ }^{\mathrm{a}} T$ test.

TABLE 4: Correlation between variables.

\begin{tabular}{|c|c|c|c|c|c|c|c|c|c|c|c|c|}
\hline Variable & $X_{1}$ & $X_{2}$ & $X_{3}$ & $X_{4}$ & $X_{5}$ & $X_{6}$ & $X_{7}$ & $X_{8}$ & $X_{9}$ & $X_{10}$ & $\mathrm{Y}_{1}$ & $\mathrm{Y}_{2}$ \\
\hline$\overline{X_{1}}$ & - & & & & & & & & & & & \\
\hline$X_{2}$ & $0.37^{*}$ & - & & & & & & & & & & \\
\hline$X_{3}$ & $0.43^{* *}$ & $0.44^{* *}$ & - & & & & & & & & & \\
\hline$X_{4}$ & $-0.36^{*}$ & $-0.53^{* *}$ & $-0.51^{* *}$ & - & & & & & & & & \\
\hline$X_{5}$ & $0.31^{*}$ & $0.74^{* *}$ & $0.58^{* *}$ & $-0.72^{* *}$ & - & & & & & & & \\
\hline$X_{6}$ & -0.18 & $-0.67^{* *}$ & $-0.57^{* *}$ & $0.59^{* *}$ & $-0.78^{* *}$ & - & & & & & & \\
\hline$X_{7}$ & -0.21 & $-0.66^{* *}$ & $-0.61^{* *}$ & $0.66^{* *}$ & $-0.84^{* *}$ & $0.73^{* *}$ & - & & & & & \\
\hline$X_{8}$ & -0.04 & $-0.34^{*}$ & $-0.40^{* *}$ & $0.44^{* *}$ & $-0.67^{* *}$ & $0.61^{* *}$ & $0.77^{* *}$ & - & & & & \\
\hline$X_{9}$ & -0.06 & $-0.29^{*}$ & $-0.43^{* *}$ & $0.50^{* *}$ & $-0.56^{* *}$ & $0.53^{* *}$ & $0.73^{* *}$ & $0.70^{* *}$ & - & & & \\
\hline$X_{10}$ & 0.10 & $0.31^{*}$ & 0.28 & $-0.47^{* *}$ & $0.33^{* *}$ & $-0.38^{* *}$ & $-0.41^{* *}$ & $-0.41^{* *}$ & $-0.44^{* *}$ & - & & \\
\hline$Y_{1}$ & $0.37^{* *}$ & $0.71^{* *}$ & $0.66^{* *}$ & $-0.75^{* *}$ & $0.90^{* *}$ & $-0.85^{* *}$ & $-0.81^{* *}$ & $-0.64^{* *}$ & $-0.53^{* *}$ & $0.42^{* *}$ & & \\
\hline$Y_{2}$ & $-0.35^{*}$ & $-0.77^{* *}$ & $-0.65^{* *}$ & $0.75^{* *}$ & $-0.91^{* *}$ & $0.84^{* *}$ & $0.87^{* *}$ & $0.67^{* *}$ & $0.53^{* *}$ & $-0.36^{*}$ & $-0.95^{* *}$ & - \\
\hline
\end{tabular}

$X_{1}$ : age; $X_{2}$ : dispatching experience; $X_{3}$ : ACC of MOT; $X_{4}$ : RT of MOT; $X_{5}$ : ACC of WM; $X_{6}$ : RT of WM; $X_{7}$ : depression; $X_{8}$ : anxiety; $X_{9}$ : perceived stress; $X_{10}$ : social support; $Y_{1}$ : overall evaluation; $Y_{2}$ : delay time; ${ }^{*} p<0.05 ;{ }^{* *} p<0.01$.

TABle 5: Stepwise regression coefficients (beta weights) for the prediction of delay time.

\begin{tabular}{lcccc}
\hline Model & Constant & $\beta$ & $P$ value & Adjusted $R^{2}$ \\
\hline Constant & 128.722 & & 0.00 & \\
ACC of WM & -89.825 & -0.33 & 0.00 & \\
RT of WM & 0.085 & 0.27 & 0.00 & 0.91 \\
RT of MOT & 0.036 & 0.17 & 0.01 & \\
Depression & 2.169 & 0.41 & 0.00 & \\
Perceived stress & -1.501 & -0.18 & 0.00 & \multirow{F}{*}{ Model } \\
Regression & 184884.57 & 5 & 36976.91 & \\
Residual & 16038.41 & 42 & 381.87 & $96.83^{* *}$ \\
Total & 200922.98 & 47 & & \\
\hline
\end{tabular}

${ }^{*} p<0.05 ;{ }^{* *} p<0.01$.

$p<0.01)$, RT of $\operatorname{MOT}(\beta=0.17, \quad p<0.05)$, depression $(\beta=0.41, p<0.01)$, and perceived stress $(\beta=-0.18, p<0.01)$, accounting for $91 \%$ of the total variance of the delay time. The result also showed the quadratic sum of regression and the residual.

In addition, Table 5 revealed that lower ACC of WM $(\beta=-0.33, p<0.01)$, longer RT of WM $(\beta=0.27, p<0.01)$, longer RT of MOT $(\beta=0.17, p<0.05)$, higher depression $(\beta=0.41, p<0.01)$, and lower perceived stress $(\beta=-0.18$, $p<0.01)$ were significantly correlated with longer delay time which indicates worse job performance. According to the stepwise regressions results, we use a statistical model that estimates the relationship between cognitive abilities, mental health, and job performance:

$$
\begin{aligned}
Y= & 128.722+0.036 X_{4}-89.825 X_{5}+0.085 X_{6} \\
& +2.169 X_{7}-1.501 X_{9},
\end{aligned}
$$

where 128.722 denotes the constant. The vector $X_{4}$ is RT of MOT, $X_{5}$ is ACC of WM, $X_{6}$ is RT of WM, $X_{7}$ is depression, and $X_{9}$ is perceived stress.

3.5. Model Test. In order to test the model of cognitive abilities, mental factors, and job performance on stepwise regression, five independent variables (ACC of WM, RT of WM, ACC of MOT, depression, and perceived stress) were considered back into the regression model. Therefore, each participant got a new predicted value of delay time. As shown in Figure 7, the threshold value $(229 \mathrm{~min}$ ) and the delay time including the original value and the predicted value were presented. In Figure 7, we observed the predicted value wandered around original value, suggesting that there was no significant difference between them. Moreover, there was a significant jump of value in 229 min between Good and Poor.

In fact, there might be a misclassification of Good and Poor. For example, there were two types of statistical errors: 


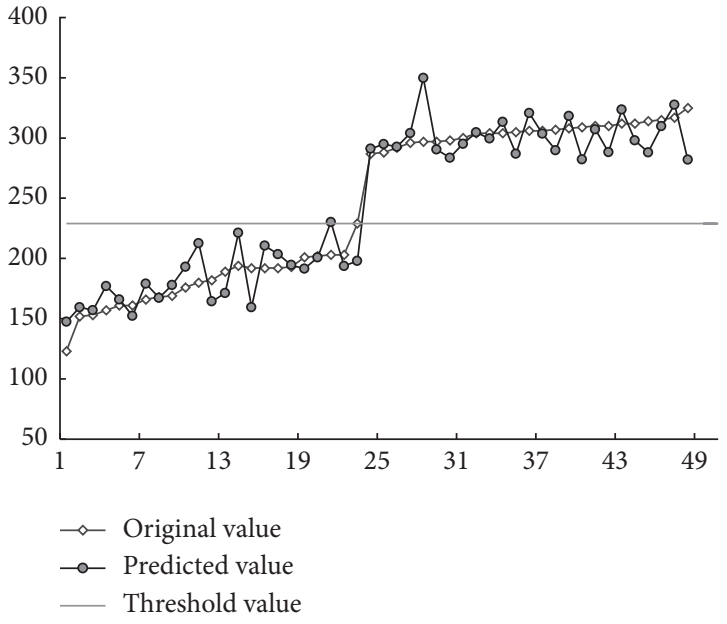

Figure 7: Comparison of the difference in delay time between the original and the predicted values.

the RWT errors and type B error, which are common errors. In order to get a more detailed understanding of the accuracy of the stepwise regression model for the division of Good or Poor, the predicted value of the participant was grouped according to the threshold value. As shown in Table 6, 96\% of the Good were correctly predicted, while $100 \%$ accurate for the Poor.

From Figure 7 and Table 6, it was apparent that the number 21 was misclassified. In order to visually present the results of difference in participant no: 21 and groups between demographic variables, cognitive variables, and mental variables, the radar map was considered. Given the disunity of scale for all variables, the min-max normalization was conducted to solve the problem by the following formula:

$$
\widetilde{x_{i j}}=\frac{x_{i j}-\min _{i}\left\{x_{i j}\right\}}{\max _{i}\left\{x_{i j}\right\}-\min _{i}\left\{x_{i j}\right\}},
$$

where $i=1,2,3, \ldots, 48, j=1,2, \ldots, 10$. By this formula, all variables were unified from 0 to 1 . Figure 8 presents the results of mean of each variable after unified scale of Good and Poor in full line and the number 21 in imaginary line. The features of number 21 were more consistent with Good. However, compared with the mean of Good, the participant's ACC of WM, RT of WM, RT of MOT, depression, and perceived stress were obviously different. The five indicators were used to predict the job performance. Therefore, the participant was misclassified.

\section{Discussion}

The goal of the current study is to examine the relationship between the cognitive abilities, mental factors, and the job performance of the Chinese HSR dispatchers. Findings showed that the multiobject ability, the working memory ability, and 2 mental factors have strong relations with the job performance (indicated by delay time), and tremendous distinctions between groups of good and poor performance of the HSR dispatchers were revealed. In addition, the
TABLE 6: Prediction rate of regression model between the two groups.

\begin{tabular}{lcc}
\hline $\begin{array}{l}\text { Predicted type } \\
\text { Original type }\end{array}$ & Good (\%) & Poor (\%) \\
\hline Good (\%) & 96 & 4 \\
Poor (\%) & 0 & 100 \\
\hline
\end{tabular}

stepwise regression modelling is employed to construct the regression equation, in which the demographic data, the accuracy and the reaction time of working memory, the reaction time of multiobject ability, the depression, and the perceived stress appeared as the independent variables and the job performance appeared as the dependent variable. The current research findings can offer indicators and models in future HSR dispatchers' selection.

Consistent with existing studies [24, 69], the positive relationship between cognitive abilities and dispatchers' job performance is supported in the current study. Working memory, which included both short-term storage and central executive control [29], is exactly what the dispatcher's job requires according to task analysis (Table 1). It is expected and understandable that working memory can significantly predict HSR dispatcher's key performance, just as working memory has demonstrated to be a good predictor for shooting behavior [70], school grades [71], and other performance [72]. HSR dispatchers should also dynamically monitor the operational status of multiple trains as well as the conditions of signals, stations, switchers, and weather, which involves dynamic visual tracking of multiobjects [73]. That leads to the ability of multiobject tracking, becoming an important predictor of job performance just as the similar job of air traffic controllers [30].

The result that mental factors were also predictors of the job performance of HSR dispatchers in this study is expected, which is consistent with results of other related occupations in previous studies [33, 34, 74]. Depression, as the most concerned mental health symptom, is associated with low self-esteem, reduced work motivation, and slower cognitive processing [33, 75]. For HSR dispatchers, depression could directly affect their subjective and objective performance indicators on the one hand. On the other hand, it could damage cognitive abilities including both WM and MOT, indirectly affecting the job performance. Although overload pressure may always accompany with fatigue, insomnia, neurological disorders, and other symptoms that cause worse performance [76], moderate pressure could also promote work motivation which leads to even better performance [74]. In the current study, perceived stress was measured. The results of more perceived stress are associated with less delay time which means better job performance. It was most probably because of the particularities of HSR dispatching work that need continuous vigilance or the relatively moderate perceived stress score (mean $=18.02$ and $\mathrm{SD}=7.76$ ). Inconsistent to other studies, anxiety and perceived social support did not enter into the predictive model of job performance $[77,78]$. This could be understandable from aspect of job analysis. In actual work, there are not many cases which require emergency dispatching though 


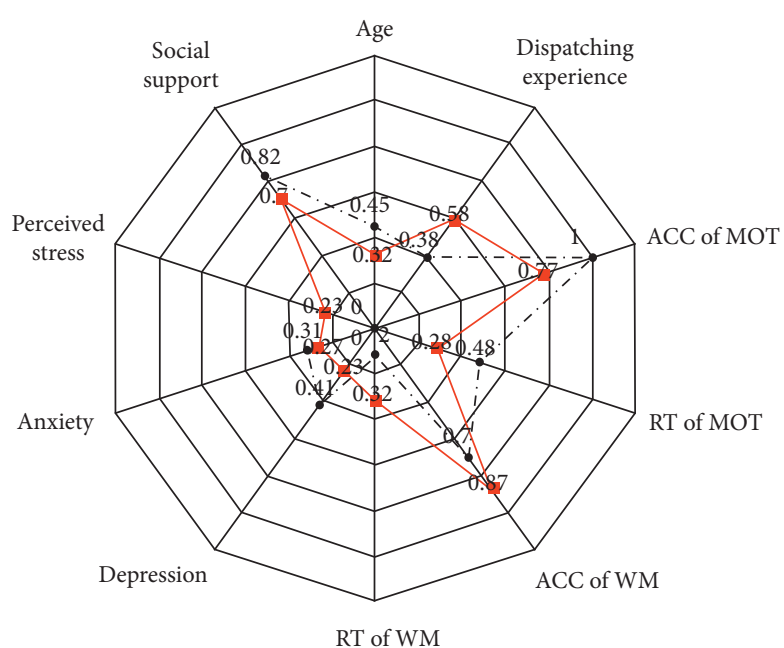

(a)

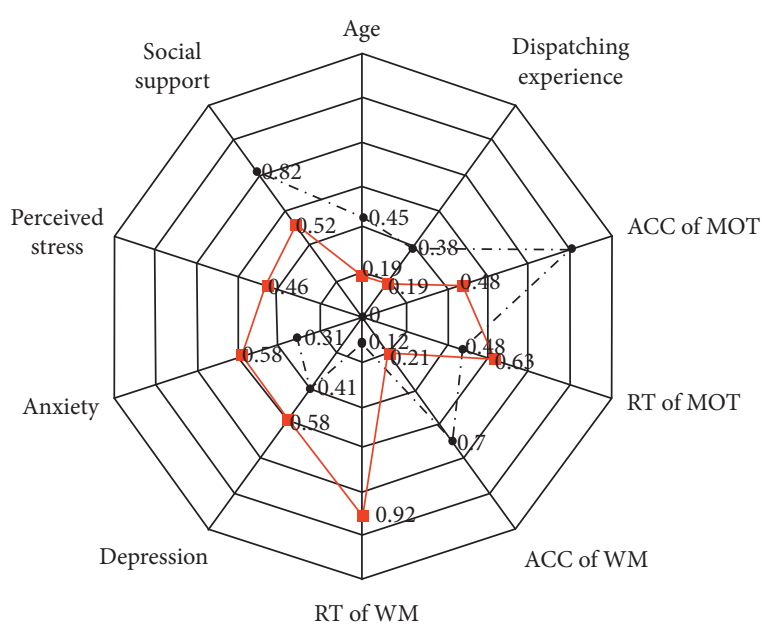

(b)

FIGURE 8: The results of mean of each variable of Good and Poor and the number 21.

constant vigilance is needed, while anxiety is mainly related to emergency situations or unmanageable events. Besides, the perceived social support scores obtained in this study were relatively concentrated in high section, while the ceiling effect makes this variable could not distinguish between the Good and Poor groups.

To summarize, the current study establishes a prediction model for the job performance of Chinese HSR dispatchers. The quantitative relationship between cognitive abilities, mental factors, and the job performance, to the best knowledge of the authors, has rarely been examined in previous study. It confirms that cognitive abilities including multiobject tracking and working memory and mental factors are important for the job performance among the existing qualified HSR dispatchers. The predictive variables including the ACC of WM, the RT of WM, the ACC of MOT, depression, and perceived stress explained an additional of $91 \%$ of the variance in the job performance. Moreover, the job performance model gets the accuracy up to $96 \%$. These findings suggest that tests of the 2 cognitive abilities and 2 mental factors may be useful tools complementary to the current practice of HSR dispatcher selection and assessment.

Although the traditional selection and assessment can investigate the dispatcher's dispatching knowledge and professional skills to a certain extent, the operational adaptability and mental factors might be more accurate potential indicators which have not yet been considered in terms of affecting the dispatcher's operational behavior safety especially in emergency scenario. Taking an emergency scenario of the dispatcher encountered an abnormal train noise, for example. However, in order to maximize the train operation, dispatchers should perform multiple tasks and organize railway personnel with different responsibilities quickly (even in seconds) and accurately. This makes dispatchers' basic cognitive abilities mainly working memory and multiobject tracking become the key factor of impacting their job performance. Regarding mental factors, the state of depression might lead to slower or less accurate reaction that would produce irreversible consequence, while perceived moderate stress would help to maintain alertness and promote more validity operation. Only when more comprehensive impact factors are included in actual HSR dispatcher's selection and assessment, our daily transportation will be safer. Therefore, building the prediction model taking both cognitive and mental factors into account is not only of theoretical significance but also of practical significance.

A limitation of the current study is that the HSR dispatchers were all from one group, China Railway Chengdu Group. Future studies are needed to examine the predictive model among other dispatcher populations such as other geographical regions in China Railway and other countries. In addition to mental factors such as depression and perceived stress, other psychological factors such as personality and motivation may also be good predictors of job performance [79]. Future studies are needed to examine these additional factors and their joint influence on the HSR dispatchers' job performance.

\section{Conclusions}

In conclusion, both cognitive factors specifically multiobject visual tracking and working memory and mental factors such as depression and perceived stress are significant predictors of the HSR dispatchers' job performance. The results from the current study provide a theoretical basis for the training of HSR dispatchers and can support future work towards establishing standardized methods and criteria for dispatcher selection and management. Additionally, the subjective and objective indicators have a high degree of consistency, which also provides a theoretical basis for the selection tools. In the next step, we will try other methods (data mining, artificial intelligence, etc.) to explore the relationship among these cognitive abilities and much more psychological factors. 


\section{Data Availability}

The data used to support the findings of this study are available from the corresponding author upon request.

\section{Conflicts of Interest}

The authors declare that there are no conflicts of interest regarding the publication of this paper.

\section{Acknowledgments}

This research was funded by the Science and Technology Program of Sichuan Province (2019YFG0043), Science and Technology Program of China Railway (2018F024), National Natural Science Foundation of China (51108390 and 71601163), and 100 Talents Program Project of Southwest Jiaotong University (grant no. 2682017WBR18).

\section{References}

[1] H. Huang, J. Chen, F. Yu, and Z. Zhu, "Establishing the enterprises' innovation ecosystem based on dynamics Core competence-the case of China's high-speed railway," Emerging Markets Finance and Trade, vol. 55, no. 4, pp. 843-862, 2019.

[2] X. Dong, "High-speed railway and urban sectoral employment in China," Transportation Research Part A: Policy and Practice, vol. 116, pp. 603-621, 2018.

[3] Y. Fan, Z. Li, J. Pei, H. Li, and J. Sun, "Applying systems thinking approach to accident analysis in China: case study of "7.23" Yong-Tai-Wen High-Speed train accident," Safety Science, vol. 76, pp. 190-201, 2015.

[4] W. Wang, X. Liu, and Y. Qin, "A modified HEART method with FANP for human error assessment in high-speed railway dispatching tasks," International Journal of Industrial Ergonomics, vol. 67, pp. 242-258, 2018.

[5] W. U. Hai-Tao and X. Luo, "Research on human error probability quantification method for high-speed railway train dispatcher," China Safety Science Journal, vol. 67, 2015.

[6] F. Chu, Y. Fu, and S. Liu, "Organization is also a "life form": organizational-level personality, job satisfaction, and safety performance of high-speed rail operators," Accident Analysis \& Prevention, vol. 125, pp. 217-223, 2019.

[7] S. Kalkavan and A. Katrinli, "The effects of managerial coaching behaviors on the employees' perception of job satisfaction, organisational commitment, and job performance: case study on insurance industry in Turkey," Procedia - Social and Behavioral Sciences, vol. 150, pp. 1137-1147, 2014.

[8] F. P. Morgeson, K. Delaney-Klinger, and M. A. Hemingway, "The importance of job autonomy, cognitive ability, and jobrelated skill for predicting role breadth and job performance," Journal of Applied Psychology, vol. 90, no. 2, pp. 399-406, 2005.

[9] Y. Yao, R. Wang, and K. Y. Wang, "The influence of emotional intelligence on job performance: moderating effects of leadership," in Proceedings of 2009 International Conference on Management Science and Engineering, vol. 14-16, pp. 11551160, New York, NY, USA, 2009.

[10] J. D. Pincus, "Communication satisfaction, job satisfaction, and job performance," Human Communication Research, vol. 12, no. 3, pp. 395-419, 1986.
[11] G. Dokko, S. L. Wilk, and N. P. Rothbard, "Unpacking prior experience: how career history affects job performance," Organization Science, vol. 20, no. 1, pp. 51-68, 2009.

[12] T. R. Carretta, "Pilot candidate selection method. aviation psychology and applied human factors," 2011.

[13] D. Gardner and D. L. Deadrick, "Underprediction of performance for US minorities using cognitive ability measures," Equal Opportunities International, vol. 27, no. 5, pp. 455-464, 2008.

[14] A. R. Kolz, L. A. McFarland, and S. B. Silverman, "Cognitive ability and job experience as predictors of work performance," The Journal of Psychology, vol. 132, no. 5, pp. 539-548, 1998.

[15] K. Anstey, J. Wood, S. Lord, and J. Walker, "Cognitive, sensory and physical factors enabling driving safety in older adults," Clinical Psychology Review, vol. 25, no. 1, pp. 45-65, 2005.

[16] A. Blane, H. Lee, T. Falkmer, and T. Dukic Willstrand, "Cognitive ability as a predictor of task demand and self-rated driving performance in post-stroke drivers - implications for self-regulation," Journal of Transport \& Health, vol. 9, pp. 169-179, 2018.

[17] D. B. Devoe, "An analysis of the job of railroad train dispatcher," 1974.

[18] J. Gertler, "Selection of railroad dispatcher candidates," 2003.

[19] E. M. Roth, N. Malsch, and J. Multer, "Understanding how train dispatchers manage and control trains: results of a cognitive task analysis," 2001.

[20] W. C. Periman, "Relationship of working memory to job performance and innovation with stress and effort as moderators," 2016.

[21] R. W. Engle, "Working memory capacity as executive attention," Current Directions in Psychological Science, vol. 11, no. 1, pp. 19-23, 2002.

[22] G. Salvadore, B. R. Cornwell, F. Sambataro et al., "Anterior cingulate desynchronization and functional connectivity with the amygdala during a working memory task predict rapid antidepressant response to ketamine," Neuropsychopharmacology, vol. 35, no. 7, pp. 1415-1422, 2010.

[23] A. M. Owen, J. Doyon, M. Petrides, and A. C. Evans, "Planning and spatial working memory: a positron emission tomography study in humans," European Journal of Neuroscience, vol. 8, no. 2, pp. 353-364, 1996.

[24] J. Wei, T. Feng, and P. Jing, "Features of multiple-objects tracking task processing in student pilots," Space Medicine \& Medical Engineering, vol. 35, 2013.

[25] R. Colom, A. Martínez-Molina, P. C. Shih, and J. Santacreu, "Intelligence, working memory, and multitasking performance," Intelligence, vol. 38, no. 6, pp. 543-551, 2010.

[26] A. M. Owen, K. M. McMillan, A. R. Laird, and E. Bullmore, "N-back working memory paradigm: a meta-analysis of normative functional neuroimaging studies," Human Brain Mapping, vol. 25, no. 1, pp. 46-59, 2005.

[27] S. Cao, U. Reiter, and M. Weitzel, "Influence of interaction on perceived quality in audio visual applications: subjective assessment with n-back working memory task," in Proceedings of Audio Engineering Society Conference: 30th International Conference: Intelligent Audio Environments, New York, NY, USA, 2010.

[28] R. Allen, P. McGeorge, D. Pearson, and A. B. Milne, "Attention and expertise in multiple target tracking," Applied Cognitive Psychology, vol. 18, no. 3, pp. 337-347, 2004.

[29] A. Baddeley, "Working memory: looking back and looking forward," Nature Reviews Neuroscience, vol. 4, no. 10, pp. 829-839, 2003. 
[30] R. M. Hope, E. M. Rantanen, and L. Oksama, "Multiple identity tracking and entropy in an ATC-like task," Proceedings of the Human Factors and Ergonomics Society Annual Meeting, vol. 54, no. 13, pp. 1012-1016, 2010.

[31] S. Harenberg, R. McCaffrey, M. Butz et al., "Can multiple object tracking predict laparoscopic surgical skills?" Journal of Surgical Education, vol. 73, no. 3, pp. 386-390, 2016.

[32] I. Legault, R. Allard, and J. Faubert, "Healthy older observers show equivalent perceptual-cognitive training benefits to young adults for multiple object tracking," Frontiers in Psychology, vol. 4, 2013.

[33] M. F. Hilton, Z. Staddon, J. Sheridan, and H. A. Whiteford, "The impact of mental health symptoms on heavy goods vehicle drivers' performance," Accident Analysis \& Prevention, vol. 41, no. 3, pp. 453-461, 2009.

[34] C. M. Wickens, R. G. Smart, and R. E. Mann, "The impact of depression on driver performance," International Journal of Mental Health and Addiction, vol. 12, no. 4, pp. 524-537, 2014.

[35] M. L. Cunningham and M. A. Regan, "Are happy drivers better drivers?" The Impact of Emotion, Life Stress and Mental Health Issues on Driving Performance and Safety, vol. 12, 2017.

[36] K. Suzuki, T. Ohida, Y. Kaneita et al., "Mental health status, shift work, and occupational accidents among hospital nurses in Japan," Journal of Occupational Health, vol. 46, no. 6, pp. 448-454, 2004.

[37] J. A. Edwards, A. Guppy, and T. Cockerton, “A longitudinal study exploring the relationships between occupational stressors, non-work stressors, and work performance," Work \& Stress, vol. 21, no. 2, pp. 99-116, 2007.

[38] M. Bubonya, D. A. Cobb-Clark, and M. Wooden, "Mental health and productivity at work: does what you do matter?" Labour Economics, vol. 12, 2016.

[39] S. Mulder and D. de Rooy, "Pilot mental health, negative life events, and improving safety with peer support and a just culture," Aerospace Medicine and Human Performance, vol. 89, no. 1, pp. 41-51, 2018.

[40] A. Hatami, S. Vosoughi, A. F. Hosseini, and H. Ebrahimi, "Effect of Co-driver on job content and depression of truck drivers," Safety and Health at Work, vol. 10, no. 1, pp. 75-79, 2019.

[41] T. A. Brown, B. F. Chorpita, W. Korotitsch, and D. H. Barlow, "Psychometric properties of the depression anxiety stress scales (DASS) in clinical samples," Behaviour Research and Therapy, vol. 35, no. 1, pp. 79-89, 1997.

[42] L. Liu and X. Dong, "Study on Mental Health status and influencing factors of OCC dispatchers in S City," Human Resource Management, vol. 2, 2017.

[43] T. A. Raslear, "Preliminary examination of railroad dispatcher workload, stress, and fatigue," 2002.

[44] N. Bolger, A. Delongis, R. C. Kessler, and E. A. Schilling, "Effects of daily stress on negative mood," Journal of Personality and Social Psychology, vol. 57, no. 5, pp. 808-818, 1989.

[45] C. Sandi, "Stress and cognition," Wiley Interdisciplinary Reviews: Cognitive Science, vol. 4, no. 3, pp. 245-261, 2013.

[46] O.-1. Siu, C.-q. Lu, and P. E. Spector, "Direct and indirect relationship between social stressors and job performance in Greater China: the role of strain and social support," European Journal of Work and Organizational Psychology, vol. 22, no. 5, pp. 520-531, 2013.

[47] M.-L. Wang and L.-J. Tsai, "Work-family conflict and job performance in nurses," Journal of Nursing Research, vol. 22, no. 3, pp. 200-207, 2014.
[48] A. A. Beaujean, S. Parker, and X. Qiu, "The relationship between cognitive ability and depression: a longitudinal data analysis," Social Psychiatry and Psychiatric Epidemiology, vol. 48, no. 12, pp. 1983-1992, 2013.

[49] C. G. La Fleur and T. A. Salthouse, "Which aspects of social support are associated with which cognitive abilities for which people?" Journals of Gerontology Series B: Psychological Sciences and Social Sciences, vol. 72, pp. 1006-1016, 2017.

[50] B. Coy, W. H. O’Brien, T. Tabaczynski, J. Northern, and R. Carels, "Associations between evaluation anxiety, cognitive interference and performance on working memory tasks," Applied Cognitive Psychology, vol. 25, no. 5, pp. 823-832, 2011.

[51] T. Ortiz, J. Perez-Serrano, C. Zaglul et al., "Deficit of cognitive event-related potentials during a working task in patients with major depression," Actas Esp Psiquiatr, vol. 31, pp. 177-181, 2003.

[52] C.-Y. Chen, J. P. Lawlor, A. K. Duggan, J. B. Hardy, and W. W. Eaton, "Mild cognitive impairment in early life and mental health problems in adulthood," American Journal of Public Health, vol. 96, no. 10, pp. 1772-1778, 2006.

[53] J. A. Hadwin and H. J. Richards, "Working memory training and CBT reduces anxiety symptoms and attentional biases to threat: a preliminary study," Frontiers in Psychology, vol. 7, 2016.

[54] S. L. Hatch, P. B. Jones, D. Kuh, R. Hardy, M. E. J. Wadsworth, and M. Richards, "Childhood cognitive ability and adult mental health in the British 1946 birth cohort," Social Science \& Medicine, vol. 64, no. 11, pp. 2285-2296, 2007.

[55] L. T. Martin, L. D. Kubzansky, K. Z. LeWinn, L. P. Lipsitt, P. Satz, and S. L. Buka, "Childhood cognitive performance and risk of generalized anxiety disorder," International Journal of Epidemiology, vol. 36, no. 4, pp. 769-775, 2007.

[56] S. Zammit, P. Allebeck, A. S. David et al., "A longitudinal study of premorbid IQ score and risk of developing Schizophrenia,Bipolar disorder, severe depression, and other nonaffective psychoses," Archives of General Psychiatry, vol. 61, no. 4, pp. 354-360, 2004.

[57] D. R. Johnson and S. D. Gronlund, "Individuals lower in working memory capacity are particularly vulnerable to anxiety's disruptive effect on performance," Anxiety, Stress \& Coping, vol. 22, no. 2, pp. 201-213, 2009.

[58] K. Smith, D. Gatica-Perez, J. Odobez, and B. Sileye, "Evaluating multi-object tracking," in Proceedings of 2005 IEEE Computer Society Conference on Computer Vision and Pattern Recognition (CVPR'05) - Workshops, vol. 21-23, p. 36, New York, NY, USA, 2005.

[59] G. A. Alvarez, T. S. Horowitz, H. C. Arsenio, J. S. DiMase, and J. M. Wolfe, "Do multielement visual tracking and visual search draw continuously on the same visual attention resources?" Journal of Experimental Psychology: Human Perception and Performance, vol. 31, no. 4, pp. 643-667, 2005.

[60] W. W. K. Zung, C. B. Richards, and M. J. Short, "Self-rating depression scale in an outpatient clinic," Archives of General Psychiatry, vol. 13, no. 6, pp. 508-515, 1965.

[61] D. A. Dunstan, N. Scott, and A. K. Todd, "Screening for anxiety and depression: reassessing the utility of the Zung scales," Bmc Psychiatry, vol. 17, p. 329, 2017.

[62] W. ., R. LINDSAY and A. ., M. MICHIE, "Adaptation of the Zung self-rating anxiety scale for people with a mental handicap," Journal of Mental Deficiency Research, vol. 32, pp. 485-490, 2010.

[63] S. Cohen, T. Kamarck, and R. Mermelstein, "A global measure of perceived stress," Journal of Health and Social Behavior, vol. 24, no. 4, pp. 385-396, 1983. 
[64] X. D. Wang, X. L. Wang, and H. Ma, "Manual of mental health rating scale," Chinese Mental Health Journal, vol. 13, pp. 3135, 1999.

[65] G. D. Zimet, N. W. Dahlem, S. G. Zimet, and G. K. Farley, "The multidimensional scale of perceived social support," Journal of Personality Assessment, vol. 52, no. 1, pp. 30-41, 1988.

[66] J. P. Meyer, S. V. Paunonen, I. R. Gellatly, R. D. Goffin, and D. N. Jackson, "Organizational commitment and job performance: it's the nature of the commitment that counts," Journal of Applied Psychology, vol. 74, no. 1, pp. 152-156, 1989.

[67] T. A. Wright, R. Cropanzano, and D. G. Meyer, "State and trait correlates of job performance: a tale of two perspectives," Journal of Business and Psychology, vol. 18, pp. 365-383, 2004.

[68] W. Darr and G. Johns, "Political decision-making climates: theoretical processes and multi-level antecedents," Human Relations, vol. 57, no. 2, pp. 169-200, 2004.

[69] K. Barker, R. Allen, and P. McGeorge, "Multiple-object tracking," Experimental Psychology, vol. 57, no. 3, pp. 208$214,2010$.

[70] G. A. Brewer, B. Hunter Ball, and J. M. Ware, "Individual differences in working memory capacity and shooting behavior," Journal of Applied Research in Memory and Cognition, vol. 5, no. 2, pp. 185-191, 2016.

[71] S. Krumm, M. Ziegler, and M. Buehner, "Reasoning and working memory as predictors of school grades," Learning and Individual Differences, vol. 18, no. 2, pp. 248-257, 2008.

[72] A. Mojzisch, S. Krumm, and T. Schultze, "Do high working memory groups perform better?" Journal of Personnel Psychology, vol. 13, no. 3, pp. 134-145, 2014.

[73] A. Tazoniero, R. Gonçalves, and F. Gomide, "Decision making strategies for real-time train dispatch and control," in Analysis and Design of Intelligent Systems Using Soft Computing Techniques, P. Melin, O. Castillo, E. G. Ramírez, J. Kacprzyk, and W. Pedrycz, Eds., Springer Berlin Heidelberg, Berlin, Heidelberg, pp. 195-204, 2007.

[74] G. Mathur, S. Vigg, S. Sandhar, and U. Holani, "Stress as a correlate of job performance: a study of manufacturing organizations," Journal of Advances in Management Research, vol. 4, no. 2, pp. 79-85, 2007.

[75] T. A. Wright and D. G. Bonett, "Growth coping, work satisfaction and turnover: a longitudinal study," Journal of Business and Psychology, vol. 6, no. 1, pp. 133-145, 1991.

[76] N. Abdoli, V. Farnia, A Delavar et al., "Mental health status, aggression, and poor driving distinguish traffic offenders from non-offenders but health status predicts driving behavior in both groups," Neuropsychiatric Disease and Treatment, vol. 11, pp. 2063-2070, 2015.

[77] P. Branscum, T. Haider, D. Brown, and M. Sharma, "Using emotional intelligence and social support to predict job performance of health educators," American Journal of Health Education, vol. 47, no. 5, pp. 309-314, 2016.

[78] T. G. Reio and J. L. Callahan, "Affect, curiosity, and socialization-related learning: a path analysis of antecedents to job performance," Journal of Business and Psychology, vol. 19, pp. 3-22, 2004.

[79] M. Guo, W. Wei, G. Liao, and F. Chu, "The impact of personality on driving safety among Chinese high-speed railway drivers," Accident Analysis \& Prevention, vol. 92, pp. 9-14, 2016. 